\title{
IMPLEMENTATION OF INTEGRATED E-LEARNING AND MICROTEACHING IN ENGINEERING: A CASE STUDY OF UNIVERSITY OF BOTSWANA
}

\author{
A. Agarwal $^{1)}$, Pitso I. ${ }^{2)}$, Dintwa E. ${ }^{3)}$ \\ ${ }^{1)}$ University of Botswana, Botswana \\ E-mail:agarwala@ub.ac.bw \\ ${ }^{2)}$ University of Botswana, Botswana \\ E-mail: pitsoi@mopipi.bw \\ ${ }^{3)}$ University of Botswana, Botswana \\ E-mail: edintwa@mopipi.bw
}

\begin{abstract}
It is indispensable for the instructors imparting competencies should have the capability to perform their task efficiently and effectively for the development of workforce skills. In this paper, we discussed the application of combining Micro-lecture methodology with the latest e-learning techniques in a core-engineering course. Audio-visual facilities enabled smart classrooms with micro-lectures using point-based videos, PPTs and images save more time for students to engage more towards practical in the laboratory and to understand the concept easily, which instigates students' interest and creativeness. This study aims to investigate the effect of using the microteaching methodology in integration with the latest e-learning techniques at the University of Botswana. To achieve this objective evolution is done by considering different pass percentages and online software-based student evolution of course and teaching system. The post-application results showed that the group showed a good rating in grades, presence and knowledge. Students rating received were good i.e. 4.2 and 4.3 in teaching and major course evolution on a scale of five with the pass percentage of $73.1 \%$ showing $23 \%$ increments from the previous year's results and excellent reviews.
\end{abstract}

Keywords: E-Learning; Microteaching; Reformation; Innovative Structure

\section{INTRODUCTION}

Educating is the course of action of possibilities of support under which students or preferably says learners can grasp the knowledge. They learn without instructing in their common habitat, however, educators organize unique possibilities which facilitate learning and hurrying the presence of conduct which would some way or another be obtained gradually or showing up of conduct which may some way or another never happen (Skinner, 1968). In the conventional showing model, learners cannot get viable chances to work, and it has decreased the productivity of the class. Educators require rehashed the trial and again which brought about the weakness and wastefulness of the instructor. Students seeing the level of fulfilment of the test are not as much as the required standard while watching the address and working research facility instruments (Wang, Luo, \& Qu, 2017).

The speciality of educating does not just include a straightforward exchange of learning from one to another. Rather, a perplexing procedure encourages and affects the way toward learning. The nature of an educator is evaluated on how much the student comprehend from his instructing. The academic aptitude for instructing can be procured just through more organized and less expensive staff preparing procedures (Foley, 1974). Since its initiation in 1963, microteaching has turned into a built-up instructor preparing strategy in numerous colleges and school areas. This preparation method is adapted towards rearrangements of the complexities of the general instructing learning process. Class estimate, time, undertaking, and materials are reduced to give ideal preparing situations. The manager shows the ability to be trained. This might be a live exhibition or a video introduction of the expertise. At that point, the 
gathering individuals select a subject and set up a lesson of five to ten minutes. The instructor learner then has the chance to hone and assess his utilization of aptitudes. Rehearse appears as a ten-minute microteaching scale showing session in which five to ten students are included (Wikipedia, 2017).

Microteaching is a strategy planning to get ready educator contender to the genuine classroom setting (Brent, Wheatley, Thomson, 1996). Microteaching can likewise be characterized as a showing strategy particularly utilized as a part of instructors' pre-benefit instruction to prepare them efficiently by enabling them to investigation primary educator practices. Micro lecture instructing is a downsized showing experience in which an instructor educates a little unit to a gathering of five students for a little time of 5-20 minutes. Such a circumstance offers a supportive setting for an accomplished or unpractised instructor to get new showing abilities and to refine old ones. With the assistance of this method, instructor competitors can analyse and take in each of the showing aptitudes by breaking them into little parts and without experiencing the confused condition of the swarmed classes. This strategy offers instructors open doors for finding and thinking about both their own particular and others' showing styles and empowers them to find out about new showing strategies (Dehejia \& Wahba, 1999).

Despite everything, it has numerous deficiencies in broadness, profundity and multifaceted nature, and advanced higher necessities for instructors' far-reaching quality. Therefore, it still needs to always enhance later on. With the steady issues in Micro-address educating is being settled, the nature of building mechanics test instructing will be enhanced incredibly (Wang, Luo, \& Qu, 2017). Microteaching is one sort of piece study assets offers to ascend to a question, that is, the way does bear on optimization development and the sensible application to meet learners customized needs (Cai, Li, \& Li, 2016).

\section{INNOVATIVE RESEARCH METHODS IN REFORMATION OF EDUCATION STANDARDS}

Researchers recommend that microteaching based elearning lessons can give a window into pre-administration instructors' intelligent procedures (Anson, Rodrigues, \& Wilson, 2003). Advanced microteaching is an instructor preparing and workforce advancement procedure whereby the educator assessments a recording of a teaching session, with a specific end goal to get useful input from associates as well as students about what has worked and what changes can be made to their educating strategy.

Fig. 1 shows the Microteaching with e-learning as an application in which video recordings have been made conceivable subsequently of creating innovation. Sound and visual innovation is a powerful and intelligent device to get ready pre-benefit instructors to the calling of enlightening. Microteaching was designed in the mid-1960s at Stanford University by Dwight W. Allen and has therefore been utilized to create instructors in all types of education (Wikipedia, 2017). Microteaching is additionally a chance to try different things with new educating procedures. As opposed to having a go at something new with a genuine class, microteaching can be a research facility to explore and get criticism, first (Kuhn, 1968). Video recordings influence the points of view of educators in the training process in a positive manner (Kalathil \& Sherin, 2000). Micro-lectures are thought to be a standout amongst the best and ordinarily received modes in mixed learning. David Penrose, who called the micro lecture an information burst, which could be utilized as a showing asset inserted in a large number of miniaturized scale learning conditions, first proposed the idea of micro-lecture-based teaching in 2008. Notwithstanding, Morris (2009) and Thomas (2009) accepted that the micro scale speech idea was appropriate in a systems administration course format (Zhang and $\mathrm{Xu}$, 2015).

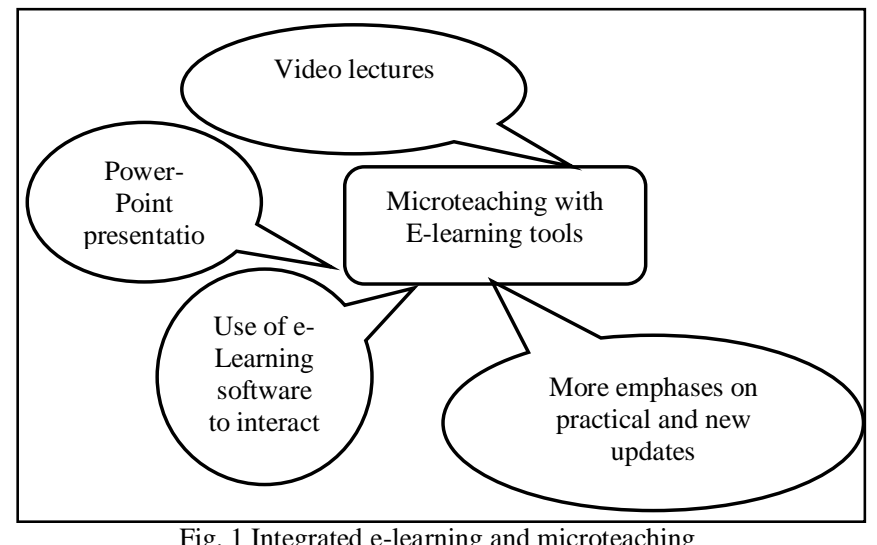

Fig. 2 briefly shows the Stepwise procedure of the effective microteaching and e-learning process. In the great Stanford model, every member instructs a short lesson, for the most part, 5 to 10 minutes, to a little gathering. The learners might be genuine students like in the first Stanford program or they might be associates assuming the part of students. The directors of microteaching sessions are the educators, speakers, understudies, teachers and different chiefs who are welcome to fill in as facilitators. Upwards of six educators from the same or comparative courses can take part in a solitary microteaching session, while one individual all the while or understudy takes his or her turn as an instructor, each other individual assumes the part of the student. Because of pre-administration instructors and showing colleagues, thereby and largely is no less than one master, also. On the off chance that coveted, the session can be recorded for the survey later. To decrease the many-sided quality of displaying it is examined into basic model exercises performed by the educator amid the instructing learning process. The fundamental goal of every one of these exercises is to advance learning among students. These exercises might clarify, outlining with illustrations, addressing, composing on the writing board, and drawing figures (Vare, 1993). Considering another aspect of ELearning, It refers to the ICT based activity utilizing Computer and programming applications to takes into consideration the vital national improvement of human 
capital through expanded access to training opportunities. Notwithstanding it is additionally worth valuing that innovation-based preparing is not at all expected to wipe out the requirement for coach drove preparing, yet it provides learners access to preparing when and where they pick (Bocodol, 2016).

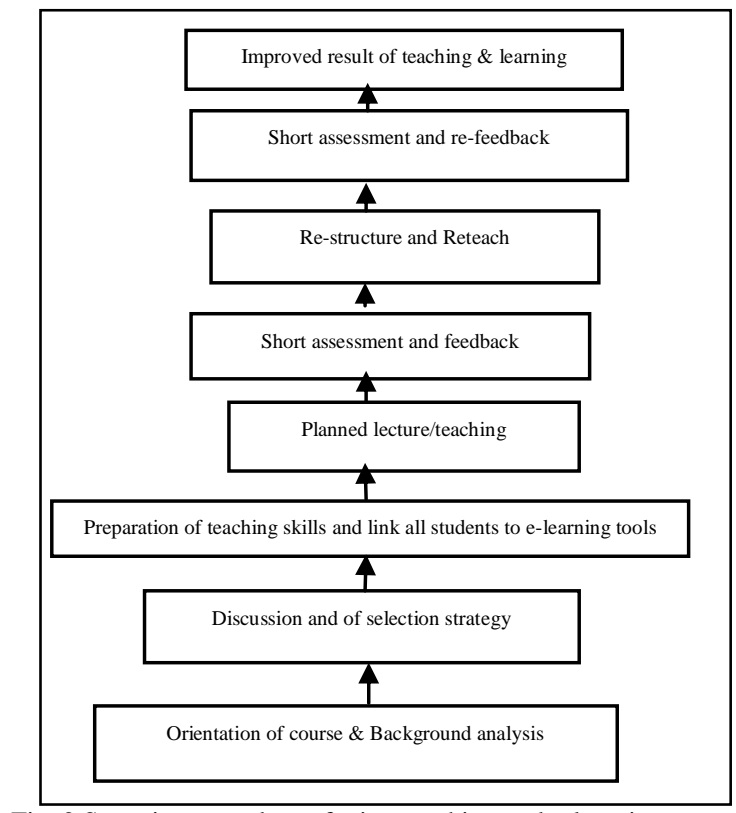

Fig. 2 Stepwise procedure of microteaching and e-learning process

\section{STRATEGIC VIEW IN HEAT TRANSFER}

Heat transfer is a practical course, which involves both theory, mathematics-derivations and practical with different laws and assumptions. This is a core mechanical engineering course and is intended to provide students with a thorough understanding of the fundamental Heat Transfer topics: also to apply the laws of heat transfer together with the correct procedure to design and analyses engineering problems concerned with heat transfer. The major aim is to give an understanding of the fundamentals of heat and mass transfer processes in engineering systems. Generally, Lecturers only have lecture time to explain in detail and students have not been exposed before when faced with experimental and practical operations. At the point when learners are restricted by the quantity of equipment, machines, it's hard to guarantee that every one of the students is completely getting a handle on information, yet forced on its special showing structure can adjust for these inadequacies. Therefore, we adopted the following strategy to apply in the course: Plan $\rightarrow$ Teach $\rightarrow$ short Assessment $\rightarrow$ Feedback $\rightarrow$ Restructure $\rightarrow$ Reteach $\rightarrow$ Re-assessment $\rightarrow$ feedback

\section{A. Course Structure of Heat Transfer at University of Botswana}

This course involves understanding the different modes of heat transfer, physical governing equations and to design heat-exchanger units for a given application, mathematical calculations and lots of practical industry-oriented approach.
However, the basic problem is that the course with more content is arranged using fewer hours. The best way is the integration of theory and practice of numerical parts in the classes, in which the teacher can demonstrate through elearning software, videos, PowerPoint presentations, and then the students do experiments in laboratories one topic by one. The combination of demonstration and practice provides a way of "learning to practice, learning in practice", which can improve students' ability to solve problems. Lecturers make their particular system module on e-learning programming portal of University's instructing stage, upload literature, Micro-address video and different materials that have finished. Therefore, the learners can download it, read it to see early, comprehend the investigation content, comfortable with lab hardware. In the wake of viewing the recordings, on the off chance that they have any challenges or any inquiries, they can remark through criticism or live visit alternative. Therefore, we tried to introduce the microlessons into classes, such as the related videos and PPT. Then students can learn the contents anytime off the classes. More classes are saved for students to do hands-on practice it also saves the requirement of revision. We divide course contents into 15 classes of 2 hours each and reserve laboratory hours as per the related topics to do practical in laboratories in a small group of 4 students but the assignment is reserved on an individual basis.

\section{B. Adoption of Integrated E-Learning-Microteaching}

To improve the ability and our reach to students combined mode of technology is applied in the form of microteaching along with e-learning tools. E-Learning refers to ICT based education provided via the Internet or CD Rom. E-Learning formats vary widely with text-only formats being the most basic. Combinations of graphics, quizzes, audio, and video components are common additions. E-Learning can be done anywhere a learner has a Computer or any communicationenabled electronic device, an Internet connection (physical or wireless) and can address needs that occur at any time (Bocodol, 2016). The first component of any strategy is collecting the background information, including its research base. It offers participants an opportunity to do a practice teaching session and receive feedback from peers within their specific discipline. Before starting the course, a small assessment is conducted to know the status and level of each student to plan the next step of teaching.

\section{Design and Preparation}

Based on the background information, the adopted teaching philosophy incorporates the following core step-bystep: Beliefs-Learning-Communication-Practice-Monitoring. For the complete courses, PowerPoint presentations were made after consulting some books and other materials to meet the objective of the course. Provided the summary, of course, aims, synopsis, mode of assessment and grading, textbooks and the reference books, dates of assignments and dates of tests. Involved in different industry-oriented topics in the course. At the starting of every lecture, 25 minutes were made a reserve for revision and remaining problems. 
We planned their labs as per the relevant topics in their course structure. For the experiments, we have divided students in the group of 4 enabling and allowing them to learn in small groups but work on an individual basis. All lessons have been well prepared and delivered. Upgrading the course material was done from time to time as per requirement. The lectures were delivered by using a projector facility, and using a whiteboard wherever necessary. Students were also encouraged to visit the Lecturer for consultations any time of the day, even outside normal working hours. Tutorials and Labs were used to give students more time to interact with taught content under supervision and guidance. Past six years question papers and links to video tutorials were available on an e-learning platform named 'Moodle' as shown in Fig. 3. It enables all users to interact with the teacher, access all contents and provides a platform to share their problems and feedback online.

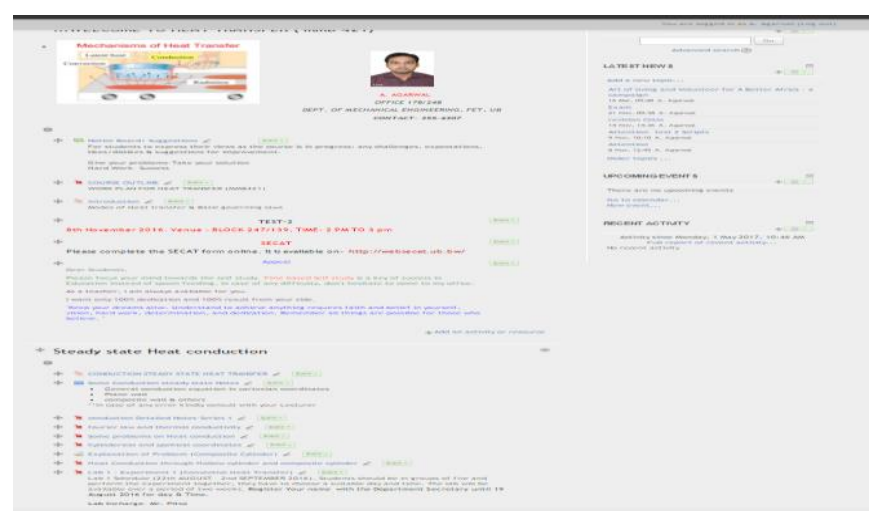

Fig. 3 Partly screenshot of arranged course contents on Moodle e-learning software

\section{Implementation and Assessment}

Fig. 4 shows the two-phase approach of the integrated microteaching e-learning process. This study employed an exploratory practical study approach aimed at providing the best available practices, processes and performance of microteaching along with the latest e-learning tools at the University of Botswana. When the students do derivations, numerical or designing, it is helpful to watch the basic diagrams, micro-videos to learn the skills. Test and learning evaluation is an important part of teaching. The assessment criteria $40 \%+60 \%$ is used as per university policy. When the Micro-lecture is introduced into the $40 \%$ part of the assessment of course, which consists of 20\% tests (two), $10 \%$ random quizzes (two) and $10 \%$ Practical in the laboratory.

Laboratory hours as per the targeted groups of students were fixed as per their convenience and a micro-class of about 20 Minutes is organized by a lab technician to demonstrate the process to perform the actual experiment on selected equipment with their applications. Assessment assumes a critical part of any undertaking.

In miniaturized scale instructing, administrators direct different test and accordingly, there are a few opportunities to investigate botches. The assessment gives a chance to comprehend the mix-up and defeat it. This program incorporates a session where disadvantages are called attention to alongside their answer. In this way, general change turns into a less demanding target Besides; unstructured discussion sessions were used to collect detailed comments and extra feedback on the implementation of the micro lecture. Online tests and online assignment submissions were conducted by using the Moodle platform.

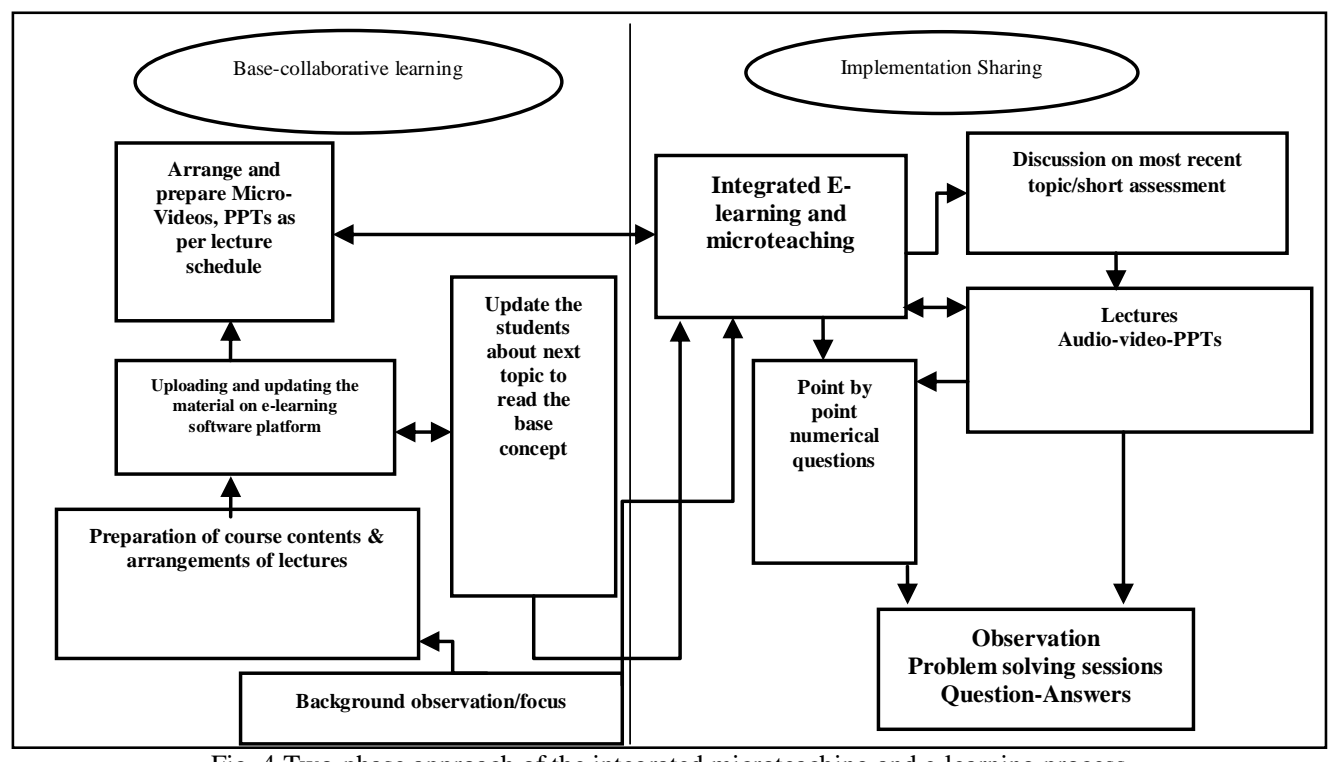

Due to the involvement of live streaming (videos) of the particular sections like the use of fins, modes of heat transfers and radiation phenomenon we generated more interest in the course by cross-questioning and by providing 
a platform to the students to share their knowledge through presentations. These implementations generated interest in the courses that class attendance was rarely below $94 \%$. The study adopted a combination of observation and an evolution and feedback comments from students through the Student Evaluation of Courses and Teaching (SECAT) online system, which was performed by every student individually. Table I and Table II show the assessment result received from the SECAT online system for a class of 26 students.

TABLE I

TEACHING Evaluation FinAL FEEDBACK

\begin{tabular}{|c|c|c|c|c|}
\hline \multicolumn{2}{|c|}{ Teaching Evaluation (Total Cases 26) } & \multirow{2}{*}{ Min. } & \multirow{2}{*}{$\begin{array}{c}\text { Average } \\
4.00\end{array}$} & \multirow{2}{*}{$\begin{array}{c}\text { SD } \\
1.07\end{array}$} \\
\hline 1 & $\begin{array}{l}\text { Helped me to learn and } \\
\text { understand the course material. }\end{array}$ & & & \\
\hline 2 & $\begin{array}{l}\text { Explained difficult concepts and } \\
\text { ideas clearly. }\end{array}$ & 1 & 4.12 & 1.01 \\
\hline 3 & $\begin{array}{l}\text { Presented course content in an } \\
\text { organized way. }\end{array}$ & 1 & 4.27 & 1.02 \\
\hline 4 & $\begin{array}{l}\text { Maintained an environment } \\
\text { where students were comfortable } \\
\text { asking questions. }\end{array}$ & 2 & 4.38 & 0.84 \\
\hline 5 & $\begin{array}{l}\text { Encouraged students to express } \\
\text { their point of view. }\end{array}$ & 2 & 4.27 & 0.81 \\
\hline 6 & Managed class activities well. & 2 & 4.12 & 0.89 \\
\hline 7 & Marked assigned work fairly. & 2 & 4.27 & 0.94 \\
\hline 8 & $\begin{array}{l}\text { Provided useful feedback on } \\
\text { assigned work. }\end{array}$ & 2 & 4.04 & 0.90 \\
\hline 9 & $\begin{array}{l}\text { Showed enthusiasm about the } \\
\text { subject matter. }\end{array}$ & 1 & 4.35 & 0.92 \\
\hline 10 & $\begin{array}{l}\text { Generated interest (of the class) } \\
\text { in the discipline. }\end{array}$ & 1 & 4.19 & 0.92 \\
\hline 11 & $\begin{array}{l}\text { Available to assist students } \\
\text { outside class hours. }\end{array}$ & 3 & 4.31 & 0.72 \\
\hline 12 & $\begin{array}{l}\text { Showed active, personal interest } \\
\text { in the progress of the class. }\end{array}$ & 1 & 4.19 & 1.00 \\
\hline 13 & $\begin{array}{l}\text { Overall, learning in this class } \\
\text { was: }\end{array}$ & 1 & 4.04 & 1.09 \\
\hline
\end{tabular}

TABLE II

Course EVAluation Final FeEdBack

\begin{tabular}{|c|c|c|c|c|}
\hline \multicolumn{2}{|r|}{ Course Evaluation (Total Cases 26) } & Min. & Average & SD \\
\hline 1 & $\begin{array}{l}\text { The course stated learning } \\
\text { objectives. }\end{array}$ & 3 & 4.42 & 0.63 \\
\hline 2 & The course was well organized. & 3 & 4.42 & 0.63 \\
\hline 3 & $\begin{array}{l}\text { The course covered stated } \\
\text { learning objectives adequately. }\end{array}$ & 4 & 4.46 & 0.50 \\
\hline 4 & $\begin{array}{l}\text { The course contributed a great } \\
\text { deal to my professional growth. }\end{array}$ & 3 & 4.46 & 0.69 \\
\hline 5 & $\begin{array}{l}\text { Course facilitated the learning of } \\
\text { problem-solving skills. }\end{array}$ & 3 & 4.38 & 0.56 \\
\hline 6 & Tutorial & 0 & 4.04 & 1.29 \\
\hline 7 & Tests. & 0 & 4.15 & 1.23 \\
\hline
\end{tabular}

\section{CONCLUSIONS}

In this study process, scrutinized management skills were applied in preparation for classes and on the quality and timeliness of feedback on assessments. As the session arrives at an end, it is trailed by a closing session. The finishing session comprises input by the instructor. Amid this session, the sound or video recording may likewise be shown with a specific end goal to give a chance to assess oneself. Additionally, it likewise helps the certainty level of the learner. It is the ideal approach to fortify the learner to work better whenever. At last, microteaching with e-learning techniques is a valuable method for instructing delicate abilities, introduction aptitudes, and relational abilities. This engaged approach empowers development through practice and study. This education teaching method is a propelled level of instructing system that empowers the educators to pick up certainty before venturing into the calling of an instructor. With the immense effect of globalization on each part of the world, there is a positively need for different schools. Proficient and compelling educating is one of the central point guardians take a gander at before enlisting their kids into a school.

Along these lines, actualizing it is showing programs for new instructors and in administration, educators are a perfect approach to set foot with the world. Upsides and downsides are a piece of each advancement and in this manner remembering those angles; one ought to pick the reasonable program. The strategy gives the staff prompt input and builds maintenance by giving them a chance to rehearse. The most imperative nature of the members of microteaching is the capacity to give and get helpful criticism with a receptive outlook and accomplishes proper educating learning objectives. This combined teaching technique empowers the educators to increase moment criticisms from the chiefs.

A moment input gives more potential for redressing botches. The combination of e-learning with microteaching goes about as a face to face learning model with an incredible open door for adaptability, coordinated effort, awesome individual consideration and IT aptitudes with high learning and educating potential.

\section{REFERENCES}

Anson, J. I., Rodrigues, S., and Wilson, G. (Jun, 2003). Mirrors, Reflections and Refractions: The contribution of microteaching to reflective practice. Eur. J. Teach. Educ., 26(2), 189-199.

Bocodol. (2016). Bocodol e-learning portal. [Online]. Available:

http://www.bocodol.ac.bw/index.php/services/elear ning. [Accessed: 04-Nov-2016].

Brent, R., Wheatley, E., and Thomson, W. S. (Dec, 1996). Videotaped microteaching: Bridging the gap from the university to the classroom. Teach. Educ., 31(3), 238-247.

Cai, M., Li, D., and Li, X. (2016). Application Research of 'Micro Lecture' Based on 'Shadow Teaching. Int. J. Inf. Educ. Technol., 6(12), 976-979.

Dehejia, R. H. and Wahba, S. (1999). Causal Effects in Nonexperimental Studies: Reevaluating the Evaluation of Training Programs. J. Am. Stat. Assoc., 94(448), 1053-1062.

Foley, R. (1974). Microteaching for teacher training. Public Health Papers. 
Kalathil, R. R. and Sherin, M. G. (2000). Role of Students ' Representations in the Mathematics Classroom. In Fourth International Conference of the Learning Sciences, 27-28.

Kuhn, W. (Dec, 1968). Holding a Monitor up to Life: Microteaching. Music Educ. J., 55(4), 48-53.

Skinner, B. F. (1968). The technology of teaching. New York: Appleton-Century-Crofts.

Vare, J. W. (1993). Co-Constructing the Zone: A NeoVygotskian View of Microteaching. In Annual Meeting of the American Educational Research Association, 106.

Wang, Z., Luo, Y., and Qu, Y. (2017). Application of Microlecture For Engineering Mechanics Experimental Teaching. 4(2), 130-132.

Wikipedia. (2017). Microteaching. [Online]. Available: https://en.wikipedia.org/wiki/Microteaching. [Accessed: 10-Feb-2017].

Zhang, X. and Xu, J. (2015). Integration of Micro Lectures into the Blended Learning Discourse in Tertiary Education. Asian Assoc. Open Univ. J., 10(2), 1328. 